\title{
A Review of Building Integrated Photovoltaic-Thermal (BIPV/T) Systems: Current and Potential Technology Development
}

\author{
Syafaruddin*, Yunita Arum Sari and Sri Mawar Said \\ Department of Electrical Engineering, Universitas Hasanuddin, Jalan Poros Malino Km. 6, Gowa 92171, Indonesia
}

Received 6 May 2020; Accepted 12 August 2021

\begin{abstract}
The paper is aimed to review several aspects comprehensively regarding the utilization of building integrated photovoltaicthermal (BIPV/T) systems published in the last five years. In this case, the considered BIPV systems includes the provision of electricity and thermal energy including the heating and cooling systems to meet the building energy demands. The reviewed aspects are the improvement efficiency by new modeling and technology advancements, the analysis of economy and environment overviews as the impact of BIPV/T installation and the system implementation and policy regarding to maximize optimal performance between the electricity energy and thermal energy captures. The comprehensive information of BIPV systems through this review article is necessary for the optimum design and future system applications, especially to researchers and practitioners involved or interested in the design, analysis, simulation, and performance evaluation and to government and stakeholders in financial and incentives supports, new methods and trends of BIPV/T systems.
\end{abstract}

Keywords: Renewable energy, photovoltaic systems, BIPV systems, BIPV/T systems, technology improvement.

\section{Introduction}

Renewable and sustainable energy generation system will be significantly directive for the future energy utilization due to the environment, self-energy utilization and low dependency on fossil fuel [1]. As one of the renewable energy sources, photovoltaic system has potential and clean energy yields for the future sustainable energy need. Recently, the photovoltaic technology as one of the considered emission-free of renewable energy source is developed fast with significant reduction of solar cell costs and efficiency improvement [2]. When photovoltaic system is integrated in building structure, only small space of building is needed compared to the wide space requirement for other type of PV generation systems [3] In this respect, the advanced utilization of PV system in building is still attractively feasible to meet partially part of the building energy loads for the provision of electrical and thermal demands [1]. The system has great potential and play important roles in distributed generation technology and significant support to the future zero energy building implementation within the critical policy and challenges [4]. For these reasons, as one of distributed generation systems, the photovoltaic system may improve the security electricity energy [3].

Recently, there have been increase in utilization of conventional building envelope materials to generate clean energy for the self-owned consumption. The system is wellknown as the building integrated photovoltaic-thermal (BIPV/T) systems [5]. In this system, the solar panels installed in the rooftops or facades of building by replacing the conventional roofs function and surface structure of building to generate electricity energy and/or heat energy for individual home consumption or distribute generation for grid connection [6]. The solution of solar panel on surface of

*E-mail address: syafaruddin@unhas.ac.id

ISSN: 1791-2377 @ 2021 School of Science, IHU. All rights reserved. doi:10.25103/jestr.144.24 building structure is highly needed in the region with hot, dry and humid conditions where cooling load consumption is very high [7]. The utilization of facade system in such climate conditions may save a significant annual electricity energy consumption for cooling system impacts to the energy cost reduction. The electricity energy capture of solar panel rooftop systems can be maximized with the optimum angle and orientation to the sunlight direction. However, the electricity energy decreases with the increase in temperature. For this reason, the thermal systems can be designed by means the provision of fluid tube for cooling system, so that the heat energy in media fluid can be simultaneously utilized with electricity energy [8].

The utilization concept of BIPV with thermal system began in the last 1980s. The technology is developed fast due to the requirement of net zero building through the application of solar energy [9]. The BIPV/T system which is growing importance for the sustainable energy utilization of buildings has changed the perception of passive envelope building structure and architectural design [10]. In this case, the system has multifunction to generate electricity energy and provide shading to the building by decreasing indoor thermal gain and lighting requirements [11]. Also, it is potentially designed for advanced window application due to the capability of heat transfer reduction, control the admitted solar heat and generating clean electricity [12]. The architectural integration of system for the optimal efficiency needs the proportions, morphology and aesthetic of the project. The direct conversion of solar energy into electrical energy with solar panel systems might be considered as the prominent technology for the renewable energy utilization. In addition, for sustainable energy application, BIPV/T system offers high flexibility of energy conservation and emission reduction [13]. The technology of conventional energy is limited while the renewable energy applications gain the maturity in the whole aspects. The optimal energy utilization of BIPV/T system is 
the main target in different countries especially for the needs of electricity energy for lighting, cooling and heating systems [14]. In the European countries, the energy consumption of building sectors reaches about $40 \%$, therefore the perception to utilize the standard building envelope components by means the BIPV/T systems to obtain energy for owned consumption. However, the barrier and risk regarding the BIPV applications have been identified and discussed in order to have the future overview of system through recommendation and development. The most significant barriers are feed in tariff, public acceptance, incentive and subsidy of government support and technical aspects regarding power loses and architecture design. Meanwhile the future perspectives are the potential for the improvement in terms of design, configuration, ventilation, positioning, guidelines and output performance prediction [15].

The compromised energy output versus the installation costs are traded-off for the beneficial analysis of implemented systems. The analysis of BIPV investigation is not far from the compromised detailed energy consumption of building and cost of installation of facade solar panel system on building [7]. Nevertheless, the BIPV/T systems offer sustainable clean energy utilization and energy provision by accommodating the potential energy sources for the target of nearly zero energy building. The supported technology and industry are developing fast regarding the solar panel improvements technology that might be attached to the building envelope structure, either on the rooftop or on the facade surface of building [16]. For instance, the latest solar cell based thin film technology which more mature and aesthetic has meaningful contribution to more advancement design of BIPV systems [4].

There are several previous reviewed papers regarding the technology development, experimental and numerical studies and impact of BIPV/T system on building performance. In this respect, researchers provide information in terms of energy production, nominal power, efficiency, type and performance assessment regarding to the new improvement technology for building integration [1]. Most articles are focused on the performance investigation and optimization of BIPV system, ventilation of PV panel for electric energy output due to the negative temperature effect on efficiency and heat transfer mechanism of systems [15]. In other perspectives, a research group provides critical review of storage systems as highly important components to be emphasized due to the potential negative environmental effects [5]. All it all, the comparison of installed location of system either on the roof top or on the wall structure of building with different media flu including the economic aspects of system is reviewed. The purpose of these review articles is to provide beneficial information regarding the advantages and limitation of technologies that could be used by researchers and engineers in the building utilization [17]. Also, it is expected that the review article may give beneficial information of research \& development, application and current and future status of technology [9].

Again, this review article attempts to provide more comprehensive information regarding several aspects of current and potential development of BIPV/T system. The reviewed aspects are the improvement efficiency by new modeling and technology advancements, the analysis of economy and environment overviews as the impact of $\mathrm{BIPV} / \mathrm{T}$ installation and the system implementation and policy regarding to maximize optimal performance between the electricity energy and thermal energy captures.

\section{Optimal Modelling and Methodology}

The sophisticated modelling and methodology are highly important to be determined in order to investigate, analysis and achieve the optimal and comprehensive electrical and thermal energy performances of BIPV/T systems. In this case, the steady and dynamic mathematical models are the main approach due to the complex behavior of systems. The intelligent computational techniques are also the optional method to overcome the unpredictable characteristic performance of systems. Meanwhile, the methodology can be overviewed from the PV circuit modelling and presented in different simulation techniques. For instance, an article explores the online technique to monitor and analyze the performance I-V characteristics of rooftops PV panels according to modified double-diode model [6]. With this proposed model modification, the system performance is only depending on the current at maximum power point with the input parameters of irradiance, temperature and wind speed. Then, other models are proposed in order to have significant gain of BIPV/T system utilization.

\subsection{Steady-State Mathematical Model}

The mathematical model is still the important method to investigate and evaluate the optimal performance of BIPV/T system. The optimization model based mixed-integer linear programming (MILP) with maximizing the net present value is applied for the BIPV with different multi-apartment building conditions with modular approach [18]. The results indicate significant energy cost saving in comparing with investment cost for building retrofitting. Similarly, the optimization model based integrated Technology Selection and Operation (TSO) is presented for distributed energy system in commercial building [19]. A steady state MILP method is formulated to optimize the proper selection, capacity and operation of photovoltaic and battery systems. As results, the TSO model is highly beneficial and powerful model for the real project evaluation due to the capability to reduce the uncertainty regarding the project cost. In different utilization of mathematical model, the thermal characteristic of BIPV/T system is well-investigated and evaluated with mathematical model based finite difference method in order to estimate the thermal parameters [20].

There is significant attention to change the perception of building design from passive to active building envelop for generating electricity and thermal energy [21]. The new innovation of BIPV with thermoelectric system on wall installation. The thermoelectric wall active system is highly adaptive to ambient temperature by reducing heat gain inside the building. In this case, the thermal model is formulated with three sub-models which consist of electric and thermal model of solar panel, heat exchange model in air duct and thermoelectric radiant model. Then the models are solved with different approaches, which are Lambert $\mathrm{W}$ function, matrix-based state space method and analytical methods, respectively. The main part of standalone BIPV system is photovoltaic-converter and battery systems. In this case, the MPPT control is unable to be applied because the output current of PV system is only depending on the state of charge of the battery bank. The Lambert $\mathrm{W}$ function as a mathematical model is applied to investigate the energy efficiency improvement according to different configuration of PV modules [22]. 


\subsection{Dynamic Mathematical Model}

Since the BIPV/T system is complex and dynamic, different approaches are performed to analysis the system behaviour. A new dynamic numerical simulation model based transient finite difference thermal network is proposed to investigate the heating and cooling energy demands including electrical energy yields for the building energy performance analysis of BIPV system on facade high building structure [23]. The simulation tool called DETECt 2.3 is able to analyse the energy integrated building issues. The main target of the study is to the recommendation to the designers and stakeholder regarding the design system in case of new building retrofitting. In addition, the computational fluid dynamics model based optimal parameters of PV layer, air duct and insulation layer are utilized to investigate the BIPV/T system performance mounted on wall/rooftop with air duct installation [24].

The electricity energy capture of BIPV system decreases with the increase in temperature. However, the performance of building solar panel can be optimized and improved with the utilization of heat energy through water fluid media at different angle orientation of semi-transparent BIPV thermal system [8]. The investigation is carried out with the periodic nature of irradiance, ambient air, cell, slab, water flow and room temperatures. The thermal comfort based the BIPVvacuum glazing materials is evaluated with one-dimensional heat transfer model in different climate conditions [12]. A dynamic numerical thermal based two-dimensional mathematical model is proposed for partial or fully integrated rooftop BIPV system considering integration structure and insulated air gap [25]. The accuracy of proposed model is measured with equivalent thermal resistance (Ross coefficient) and compared with the operating cell temperature thermal model from manufactured data sheet and measured data.

\subsection{Computational Intelligent Methods}

The computational intelligence methods have been used in optimization and improvement performances of BIPV/T system. The artificial neural network, genetic programming and adaptive neuro-fuzzy inference system were used for prediction of energetic performance [26]. In this case, the BIPV thermal system has capability to provide cooling system to PV panel and generate electricity during winter and summer. Due to the simplicity of concept/application and robustness, the genetic programming method is more accurately formula than other two methods. Similarly, the energetic and exergetic performances improvement on glazed/unglazed BIPV thermal systems is investigated with multi-objective optimization based genetic algorithm [27]. The target of this optimization approach is to find the optimum values of geometric parameters of systems and air mass flow rate within the maximum annual average efficiency. Another approach, the optimized artificial neural network and particle swarm optimization is utilized for estimating the energy performance of BIPV systems by taking geometric duct and air mass flow rate as the input parameters [28].

\subsection{Simulation Tools}

The TRNSYS software is quite popular for the energy management strategy, thermal performance and comprehensive energy production of BIPVT/T system. The analysis and optimal approach of photovoltaic and battery system are conducted in low energy building installation [29]. The energy management strategy based TRNSYS is performed considering the battery life cycle, grid operation and electricity price. The optimizing with single and multiobjective functions are proceeded for technical, economic and environmental performances based on decision making strategy. The single criterion is benefit for the performance of energy supply, battery storage, utility grid for the target building. Meanwhile, the multi-criterion is important for the PV self-consumption and efficiency, net grid energy, battery life cycle, gas emission. In different approaches, the performance of variable capacity air source heat pump coupled with BIPV/T system on wall installation is theoretically investigated. The air is circulated under the solar panel through duct system in order to capture the thermal energy. The TRNSYS is used to evaluate the thermal performance under heating mode operation [30].

Meanwhile, the efficient integration approach of BIPV/T system with heating, ventilation and air conditioning (HVAC) system including the thermal storage is presented for the highperformance solar energy application in buildings [31]. A model predictive control algorithm is utilized for the dynamic model of systems to determine the optimal set-point trajectory of thermal storage tank and to evaluate the energy saving potential at the heat pump. A comprehensive energy yields model is developed in TRNSYS to identify the parameters of low-order linear time invariant state space model. Another simulation tool, the PVSYST software is utilized to determine the optimum orientation of BIPV facade system installation with the objective functions of minimum cooling load and maximum electricity energy output. The other parameters considered in the study are building size, space layout dimension including shape and orientation of facade PV systems [7].

\subsection{Thermal Periodic Theory}

A thermal periodic theory in [32] is applied in BIPV with semi-transparent PV thermal system where energy balanced equation of overall system components is formulated [33]. Due to the solar irradiance and air temperature are periodic in nature, then all temperatures will be periodic as well. With the energy balance equation, all temperatures are setup in matrices that represent time dependent and independent part of basic equation. Then, the problem is solved by the matrix inversion method. Similar approach of thermal periodic theory-based energy balance equation is proposed when considering the intermittent water flow [34]. In addition, the simultaneous effect of heat capacity and water flow is studied in semi-transparent photovoltaic modules [35]. In this case, the analytical expression of temperatures (room air, floor, solar panel, water tank, tank, water on roof), solar cell efficiency, daylight saving and electricity energy is derived. Comparative analysis is performed with and without water flow in order to understand the cooling effect by water flow on the rooftop.

In fact, there is a trade-off between simulation speed and accuracy in order to deal with optimal parameters in complex system, such as BIPV with thermoelectric wall-system [36]. The main aims are to determine an accurate and fast simulation method of this complex system. In this proposed system, there is an optimal balance between time step of simulation and superposition number to obtain the annual thermal performance. It is obtained that the non-uniform time step model can be useful for other BIPV thermoelectric wall system installation. The BIPV with thermoelectric wall system is an effective and innovative BIPV system which may reduce building energy load significantly. The thermoelectric wall system can provide heating/cooling and generate electricity simultaneously [37]. In this respect, the integration 
parameters of solar panel for irradiance transformation, air gap for thermal dissipation and thermoelectric panel system for active cooling/heating end up the BIPV with thermoelectric wall system become perfect and complex systems [38].

\section{Advanced and Innovation Technologies in BIPV/T systems}

The technology of BIPV/T system is fast developing to achieve high efficiency electrical and thermal performance of BIPV/T systems. The simple way of technology applications is to apply the optimal orientation of system to the sunlight direction called the optimal tilt angle of system and application of multiple duct system for media fluid circulation. The radiative cooling, heat pipe system, thermal wheel, and smart window system can be considered as the innovation technology in BIPV/T system. Nevertheless, the fastdeveloped technology solar cell in semi-transparent thin-film solar cell can accommodate the balance between electrical and thermal energy utilization of BIPV/T systems. Also, the application of concentrating solar cell is remarkable to achieve the high efficiency performance and maturity utilization of BIPV/T systems.

\subsection{Optimal Tilt Angle Systems}

The technology of BIPV/T system is developed fast and implemented to achieve net zero energy of buildings. The electrical and thermal efficiency are improved by the structure elements and air duct beneath the solar panel for the air flow [39]. Overall, the efficiency performance of BIPV/T system is depending on the several factors, such as site, level of irradiance, direction of the collector surface to sunlight, tilt angle of the system and ventilation of the air gap between the solar panel and the building cover [40]. The overall performance of systems in terms of temperature distribution can be investigated from the energy efficiency and exergy efficiency overviews. In fact, most numerical studies of these two efficiencies are based on the PV/T systems, water systems and mechanical ventilated air systems. Especially for orientation of panel to sunlight direction, the optimum tilt angle as in Fig. 1 based the solar insolation is used in energy equilibrium equation for mathematical model of thermal system. Meanwhile, different mass flow rate is considered for the electrical and thermal energy performance of BIPV/T system at optimum tilt angle [39]. In this respect, the predictive model-based particle swarm optimization can be utilized to optimize the tilt angle of system with the objective function of maximum power generation, indoor illumination while minimum indoor temperature for zero energy building [11].

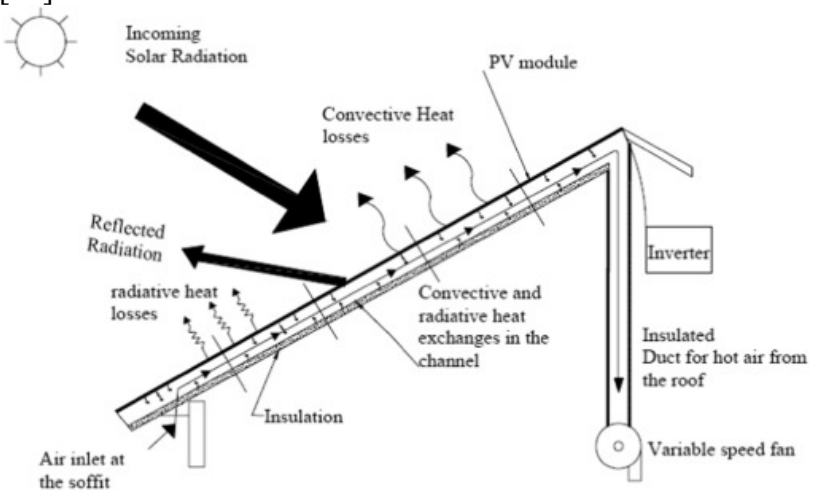

Fig. 1. Tilt angle on the rooftop of building [9].

\subsection{Multiple Inlet Duct Systems}

The performance investigation on number of intake air is considered to improve the thermal efficiency of BIPV/T system (Fig. 2). The thermal behaviour of two-inlet air-based open loop BIPV/T system is experimentally studied using full-scale solar simulator [42]. The proposed two-inlet system with frameless solar panel can improve the thermal efficiency compared to the conventional one-inlet systems without any additional costs of installation. Also, the proposed system might improve the thermal efficiency of semi-transparent PV system due to both direction of sunlight absorption. In fact, the air based open loop BIPV/T systems are efficient for generating electricity and producing useful thermal heat simultaneously.

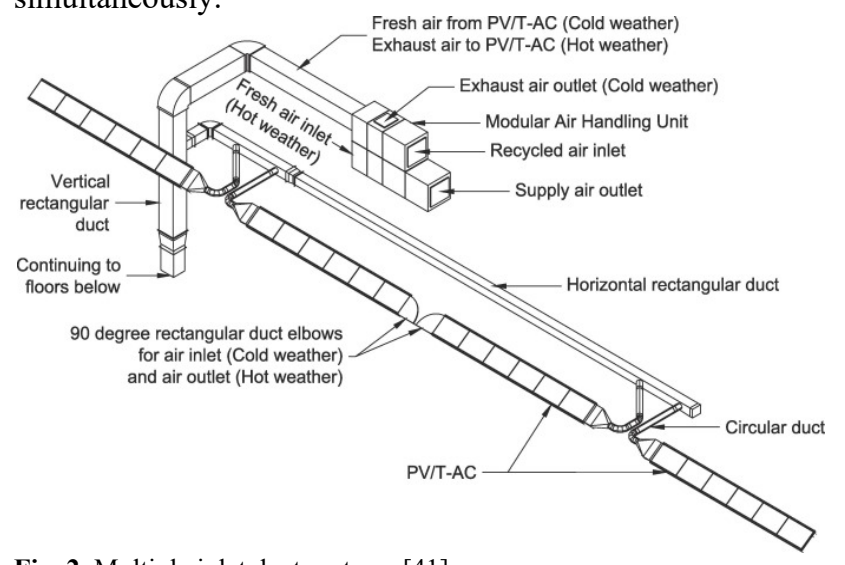

Fig. 2. Multiple inlet duct systems [41].

However, the heat transfer capability of air is low, so that it may reduce the system efficiency, promote overheating impacts to short life span utilization. With introducing multiple air intake duct along the PV string, it is expected better heat extraction and achieving lower and uniform temperature [43]. The numerical investigation is carried out to compare the single and multiple air intake in BIPV/T system for possible future building renovation in large scale installation. A flow distribution model is utilized to investigate the factors of pressure drop and flow correlation including the wind tunnel pressure for the electrical and thermal energy performance.

\subsection{Radiative Cooling - Radiative Forcing}

Technology of BIPV/T system combined with radiative cooling is proposed to maximize the potential rooftop open space that exposures to sunlight direction regarding the annual total energy output [44]. In this respect, the BIPV with thermal system has been attracted for researchers because the capability of system to generate electricity and thermal energy at the same time [45]. However, the space cooling is limited for building in hot regions, while space heating is less needed. The integration of BIPV system and radiative cooling (Fig. 3a) is proposed where the PV system generates electricity during daytime and radiative cooling generates cooling energy during night time. The performance of proposed system is analysed with quasi-steady-state mathematical model under real ambient weather conditions. The study results indicate that the amount precipitable water vapor from radiative cooling system is not a problem in the dry climate condition. In comparison to radiative cooling, the externality of PV system installation is investigated in the form of radiative forcing (Fig. 3b) regarding sunlight absorption on Earth's surface. When radiative forcing is considered in the economic and environment factors, the PV system technology 
is put in the low-cost system, high efficiency installation and low contribution to global warming [2].

\subsection{Heat Pipe, Thermal Wheel and Smart Window} Systems

The Innovation technologies in terms of heat pipe system, thermal wheel and smart window systems has put the BIPV/T system at the high optimal performance of electrical and thermal energy systems simultaneously. The innovation technology of heat pipe is utilized in BIPV thermal system is investigated with dynamic mathematical model for electricity generation, services heat water, air conditioning load reduction [46]. The study concludes that the BIPV/T with heat pipe system presents attractive energy performance and adaptively to different climate conditions. Meanwhile, the feasibility integrating of BIPV/T system with thermal wheel is investigated for the residential applications. The innovation technology is able to provide pre-heating/cooling of ambient air during winter/summer as well as producing electricity [47]

The multi-objective optimization method is used to determine the optimal geometric and operating parameters with the target of maximum performance of thermal wheel and efficiency of overall BIPV/T systems. In addition, the new concept of BIPV system with concentration photovoltaic with smart window system is proposed to adaptively respond to the environmental conditions by balancing provision between solar irradiation for electricity energy, daylighting and heat energy of buildings [48]. The successful application of smart window system is highly depending on the optimal relationship between transmittance and reflective properties of thermotropic layer.
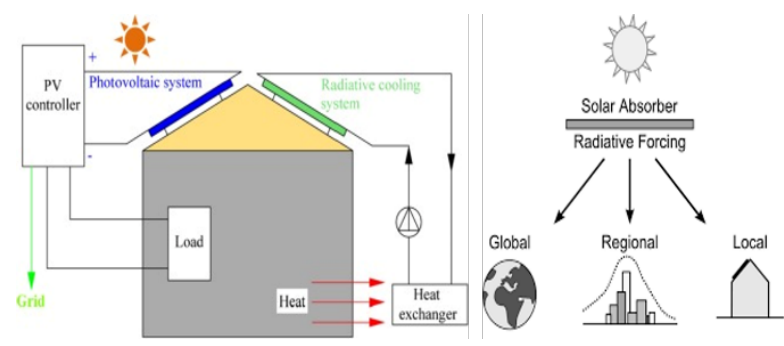

a. Radiative cooling [45]

b. Radiative Forcing [2]

Fig. 3. Radiative cooling and radiative forcing

\subsection{Earth-Air-Heat Exchanger (EAHE)}

The performance of BIPV/T system can be improved by integrating with thermoelectric radiant system with PV module installed in wall structure of building [49]. The numerical results indicate that a significant reduction of annual energy usage for heating/cooling loads. Therefore, the proposed BIPV with thermoelectric system has potential to promote zero energy and low exergy building.

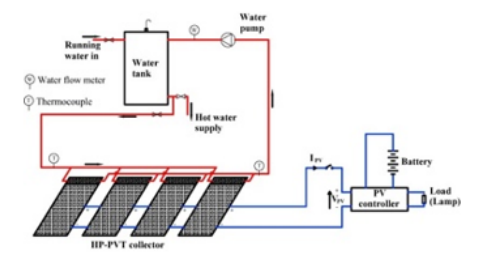

a. Heat pipe systems [46]

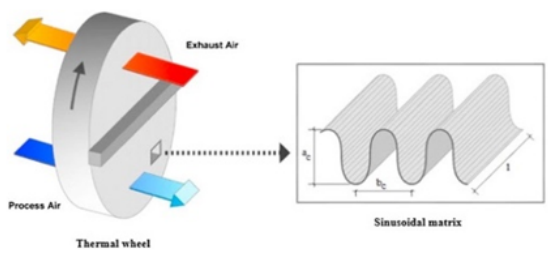

b. Thermal wheel [47]

Fig. 4. Heat pipe, thermal wheel and smart window systems.

In this respect, the multi-objective optimization is implemented to the optimal operation of hybrid BIPV thermal system with earth-air heat exchanger (EAHE) for the heating and cooling modes [50], [51]. The objective functions are the annual energy and exergy production to obtain the optimal parameters, such as air mass flow rate, the volume parameters of BIPV thermal channel and the length and depth parameters of EAHE.

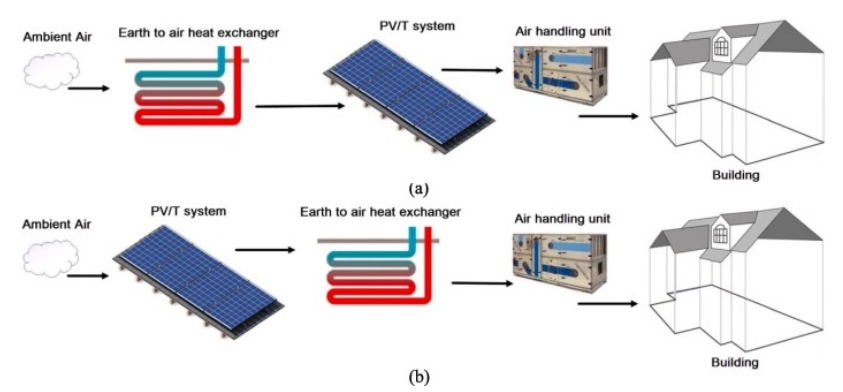

Fig. 5. Earth-Air-Heat Exchanger systems [50].

\subsection{Semi-Transparent Thin Film Solar Cells}

Semi-transparent thin film solar cells are widely used in BIPV/T technology due the capability of simultaneous electrical and thermal energy management including the daylighting provision. A comparative analysis of BIPV/T system is performed between the conventional rooftop solar panel and semi-transparent photovoltaic thermal in terms of useful thermal gain and thermal load levelling for thermal comfort [52]. Semi-transparent photovoltaic for BIPV/T system is able to collect thermal energy and provision of daylighting in room building [53]. The efficacy model is presented to measure the variation is cell and room temperatures taking the consideration of number room air change per hour. Nowadays, technology development of semi-transparent thin-film solar cell for BIPV system-based window installation is focused on hydrogenated amorphous Silicon [54]. With this technology, the wide-bandgap and conductive window layer are introduced in order to improve the quantum efficiency under shortwave length and light transmittance.

The electrical energy demand increases due to the needs of lighting and cooling in most buildings. It impacts to the emission problems and environmental degradation after utilization of conventional power generation for supplying energy. For this reason, it is necessary to have cooling systems to maintain the indoor thermal condition in order to reduce the energy consumption for cooling the buildings [55]. The thermal model of passive cooling system, such as evaporative cooling, natural ventilation, daylight and heat storage capacity for BIPV with semi-transparent photovoltaic thermal systems. In addition, the parametric study for cooling purposes of semi-transparent photovoltaic thermal based 
BIPV system is investigated under hot climate conditions [56] The cooling parameters, such as heat capacity, water flow and daylighting are formulated in single model to obtain the other parameters like temperature, electricity energy production and solar cell efficiency.

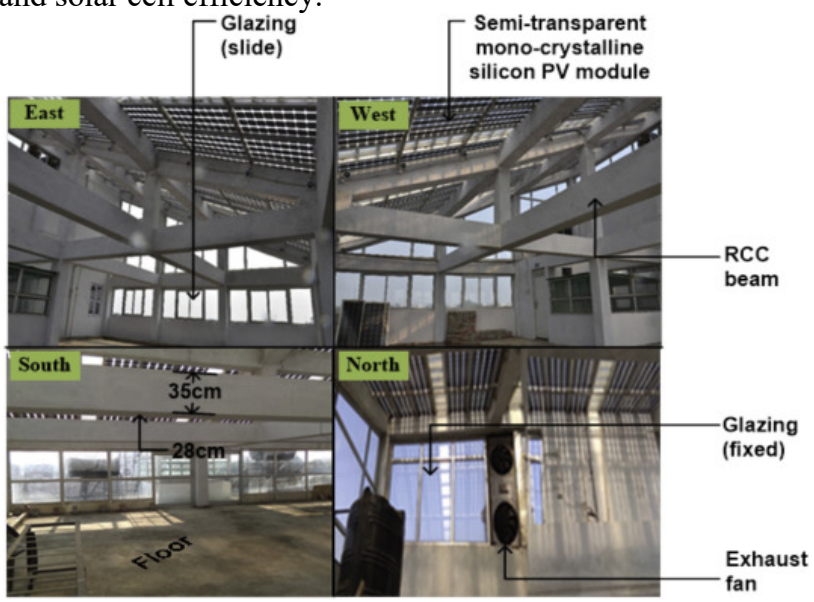

Fig. 6. Semi-transparent solar cell technology for BIPV/T system [53].

\subsection{Concentrating Photovoltaic Systems}

The operation BIPV with concentration of PV system is optimized for the maximum energy generation and provision of daylighting of building space simultaneously [57]. It is obtained that the performance of concentration solar panel and concentration solar panel along with daylighting purpose is similar at various incident angle of sunlight and no effect to the optical performance of the concentrator. In terms of technology, he optimal design of concentrating solar panelbased compound parabolic concentrator with V-trough geometry is simulated to improve the light absorption with less material manufacture in different optical efficiency using ray tracing modelling produced by the COMSOL Multiphysics [58]. Also, BIPV system with concentrating photovoltaic is proposed to benefit the reflective and refractive solar radiation in building utilization [59]. The simulation of Monte-Carlo ray trace is used to model and optimize the design of optical geometry based threedimensional cross compound parabolic concentrator. In addition, the detailed modelling of BIPV performance with concentrating photovoltaic system is evaluated based on the optical, electrical and thermal analysis. In this system, part of concentrated light is converted to electricity and rest is dissipated in the form of heat [60].
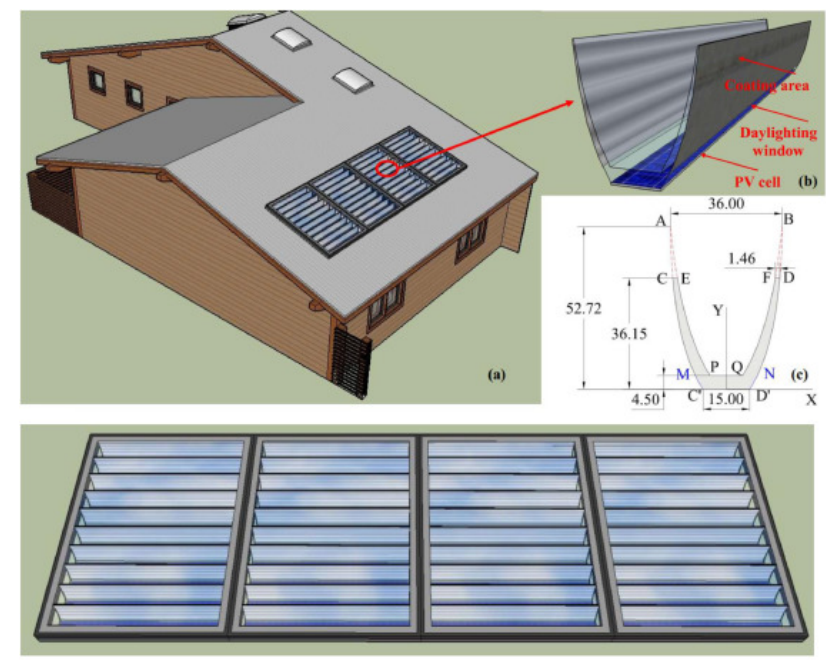
(d)

Fig. 7. Concentrating solar cell in BIPV/T systems [57].

\section{Technical Challenges including Management of Storage Systems}

This section provides collective information regarding the challenges in distribution network when the BIPV/T system is connected to the grid. Also, the discussion of shading in micro level by means in the solar cell design and in macro level by the shading object of building which influences the $\mathrm{BIPV} / \mathrm{T}$ performances are provided. The section is end up with the management of electrical and thermal storage systems, especially when the phase change material (PCM) is utilized.

\subsection{Challenges in distribution network}

The motivation of BIPV system installation is to obtain the energy sustainability by maximising the potential of surrounded energy availability [61]. Another approach to optimize the BIPV facade system performance is by integrating with energy grid building. The consideration of supplying AC or DC energy to the grid building especially for the location with high solar energy yields is promptly discussed due to the mature of renewable energy sources utilization and the increase in DC loads applications including the electric vehicles. However, the connection of solar panel from BIPV system to grid may cause risk problems in distribution network due to the variability output [14]. To overcome this condition, the provision of reactive power from voltage source inverter is the prominent solution and is claimed to be stable, reliable and cost-effective system rather than controlling the VAR compensation on distribution grid. Due to the intermittency output of PV systems might cause severe impacts to the utility operation, the BIPV system especially for the grid connection is questionable [13]. The problem is optimized by the iterative algorithm and linearized technique for the combined energy-water supply systems with target of minimum energy cost consumption and power volatility to meet the water demand.

\subsection{Shading Problems}

The electricity generation in BIPV system is rather complex compared to other type PV generation systems [62]. The insolation on the tilt surface, solar panel temperature, the DC and $\mathrm{AC}$ power are measured to obtain the energy yield of the building. Also, the investigation of the optimal system performance is proceeded due to complex shading problems, improved solar panel connection and temperature characteristics when the BIPV system are simultaneously function as the insulating glazing for the lighting transmittance. In micro level, the air layer which exist between the glass covers and cells in BIPV with thermal systems reduce significantly the heat loss and enhance the thermal efficiency [63]. However, the frame border that holding the glass cover creates shadow the cells near the frame according to air layer thickness, direction and sun position which affects the performance of photovoltaic cells. BIPV with thermal system is a prominent system for urban applications to achieve net zero energy building by capturing the solar irradiance [64]. However, the shadow which may come from the surrounded building at close proximity can reduce the thermal performance of BIPV system due to significant influence of shading and sky view blocking effects to the sunlight direction. Therefore, the optimum tilt angle, solar light intensity and performance of BIPV system are important to be evaluated in the presence of shading objects. 


\subsection{Management of Storage Systems}

The combined BIPV systems with energy storage can improve the overall system in terms of peak demand reduction, power quality and power distribution allocation [65]. Therefore, the optimal size of battery would reduce the total cost of investment and the dependency to grid supply. The optimal capacity of battery is determined by real time operational data between BIPV system power production and load consumption considering the maximum reduction of annual electricity bill. The economic and technical performance are evaluated for the application of on-site battery energy storage system based BIPV system within power grid supply limit with reasonable energy tariff for minimizing annual energy cost [66]. It is due to the installation of battery unit by the BIPV system owner will impact to the additional investment. In fact, there is significant relationship between the electricity production from PV panels and supply energy from the grid. In addition, different scenarios of battery energy storage system capacity are examined in order to test the sensitivity of the performed analysis [61].

The effectiveness of renewable energy use in BIPV or $\mathrm{BIPV} / \mathrm{T}$ systems is highly depending on the energy storage utilization. The review of energy storage is presented in [5] considering multiple storage solution in different material, such as battery, phase change material (PCM) and different type of installations, such as non-concentrating system, roof and facade locations with water and air of media fluids. Both systems are correlated to the environmental effects of storage utilization, such as material manufacturing, accidental release of electrolytes, inhalation toxicity, flammable elements, degradation and end-of-life management for battery critical factors. The technology integration of PCM into BIPV with transparent photovoltaic system is promising to control the improved surface temperature of PV panel. However, there are so many chemical compounds called eutectic mixtures are utilized to regulate the cell temperature [67]. Regarding to phase change material (PCM) components, some corrosive materials in heat water storage, fire-safety issues as well as high toxicity in terms of human health and ecosystems are considered. Nevertheless, BIPV system incorporating with phase change material (PCM) offers potential of reducing the solar panel temperature and provide such radiator of cooling system to improve the electrical efficiency of PV system. Also, the heat absorbs by the fluid media can be utilized for building energy utilization [68]. The numerical study has been conducted taking the input parameters of BIPV and PCM in order to maximize the total electricity energy yields and heat energy within the constraint of maximum accepted solar panel temperature.

BIPV system is easily integrated with surrounded environment, replacing building material structure in order to benefit the electric and thermal energy including the daylight provision though building envelope [69]. In this case, the phase change material (PCM) is experimentally evaluated to improve the low concentration BIPV system through thermal regulation and to discuss the impact of PCM temperature on electrical parameters of BIPV system. The previous research is correlated to the temporal and spatial studies of PCM temperature of BIPV system. As results, he utilization of phase change material in photovoltaic system improve the energy efficiency conversion by providing cooling system on solar panel and keeping the indoor heat transmission [70]. The impact of PCM layer is experimentally investigated for the electrical and thermal performance of PV system and indoor space temperature.

\section{Analysis of BIPV/T system: Energy, Exergy, Economy and Environment (4E)}

\subsection{Energy-Exergy Analysis}

The optimal performance of BIPV/T systems can be achieved with detailed investigation and analysis of energy-exergy of system. The numerical investigation is applied for the potential cooling of PV system for high efficiency energy conversion which is obtained from the supply and exhaust air, while the heating can be produced from the heat rejection of panels [71]. In BIPV system with semi-transparent photovoltaic thermal, the exergy analysis of is proposed for considering constant room temperature with different number air changes between room and ambient air [72]. The energy balance equation is analytically designed taking the complete parameters of semi-transparent photovoltaic system, floor and room air following the solar cell electrical efficiency. Another investigation, the experimental and theoretical studies is discussed considering the utilization of air duct [73]. The research measurement includes the system behaviour, energy and exergy analysis regarding the electrical and thermal energy output in order to obtain the optimal parameters of geometry of air duct, media fluid velocity, packing factor and number of air changes. An example, the assessment and analysis of energetic and exegetic performances is proposed for of BIPV system with waste water source heat pump [74].

\subsection{Economic-Environment Analysis}

The volatility and uncertainty prices of electricity price makes reducing the interest of PV installation investment [3]. In this reason, the investor looks for the optimal decision regarding the investment cost while search different methods to improve the system values, such as the optimal size and timing of installation in BIPV system. The technical and economic impacts of house retrofitting with BIPV/T installation is evaluated to estimate the energy savings, gas emission reductions and reasonable costs of investment [75]. In BIPV/T system, photovoltaic system generates electricity for building energy utilization, while the energy excess sends to the grid through market mechanism. Meanwhile, the thermal energy is used for thermal demand and domestic hot water provision. In this regards, significant numbers of old multiapartment building in Europe which are energy inefficient become the important case to be discussed in terms of restoration for the economic reason regarding the profitability and optimal size of different renewable energy utilization [18].

The economic analysis of innovative BIPV system approach is presented to quantify the social and environmental advantages of system in terms of life cost analysis [16]. The results yield that the economic feasible is clearly obtained from the socio-environment point of views when the conventional function of building structure is replaced with the BIPV systems. The characteristic of environmental impact of BIPV system with different scenarios of PV operation is evaluated with life cycle analysis and compared with conventional generation unit to producing electricity [76]. An example, the procedure of determining the proper size and cost of integrating thermoelectric air-cooling duct and photovoltaic system on wall in tropic climate conditions is proposed based on the life cycle assessment with the target of minimum economics and energy consumption [77].

Utilization of renewable energy based BIPV system has attracted and received great attention from researchers and great financial support of government [54]. Regarding the energy payback time which less than the PV system life 
utilization, the PV system has long sustainable and environmentally friendly from the energy consumption overviews. Life-circle cost analysis and energy payback time is performed for $\mathrm{BIPV} / \mathrm{T}$ system-based modification of irradiance and optimal tilt angle considering the shadow effects [78]. The electrical and thermal performance of semitransparent PV system are evaluated for different air mass flow rate through series duct combinations. Meanwhile, the life span operation including the energy payback time is evaluated with different orientation to sunlight directions. The shadow has no significant effect to the life cycle and energy payback time of system due to the existence of flow duct beneath the solar panel. Therefore, the BIPV/T system is economic and environmentally feasible for renewable energy source utilization [79].

The solution of environmental problems in terms of decarbonising is one of the main challenges and effort of all stakeholders to tackle the climate changes [19]. One of the solar energy applications is the building integrated photovoltaic (BIPV) system. Meanwhile, one type of popular BIPV systems is the BIPV with thermal system or BIPV/T [17]. BIPV is investigated with and without media fluids (air or water) for cooling PV panels to increase the electricity energy efficiency before exhausting to the ambient. With $\mathrm{BIPV} / \mathrm{T}$, the collected thermal heat from the media fluid is used for heating and drying purposes. The application of BIPV/T system for drying system is developed considered the optimal basic configurations of photovoltaic laminating layer and insulated air gap [80]. The modification of BIPV/T system leads to the thermal heat generation that decreases the electrical performance. Therefore, it needs the heat absorber at the backside of PV panel in order to optimize the heat transfer surface at PV lamination layer.

\section{Final Remark - Supporting Systems}

The successful Implementation of BIPV/T system needs regulation and constant support from the government or decision makers and other stakeholders in terms of technology, rational finance and policy. In this respect, the subsidies and financial incentives might be highly needed to motivate the positive efforts for the costs of building restoration measurement. Through this review results, comprehensive information of BIPV/T system is necessary for the design and future system implementation, especially for the location with critical climate conditions. In this case, the prediction of thermal behaviour of BIPV/T system is highly important and would be the future important regulation and business model. In the end, the review article provides important reference and guidance for the optimal energy management of PV with storage system in BIPV/T systems. Therefore, the proliferation PV system installation in urban areas can be significantly quantified.

This is an Open Access article distributed under the terms of the Creative Commons Attribution License.

\section{References}

1. Emrah Biyik, Mustafa Araz, Arif Hepbasli, Mehdi Shahrestani, Runming Yao, Li Shao, Emmanuel Essah, Armando C. Oliveira, Teodosiodel Caño, Elena Rico, Juan Luis Lechón, Luisa Andrade, Adélio Mendes, Yusuf Baver Atlı, 'A key review of building integrated photovoltaic (BIPV) systems', Engineering Science and Technology, an International Journal, Vol. 20, Issue 3, June 2017, pp. 833-858

2. Brian R.Burg, Patrick Ruch, Stephan Paredes, Bruno Michel, 'Effects of radiative forcing of building integrated photovoltaic systems in different urban climates', Solar Energy, Vol. 147, 1 May 2017, pp. 399-405

3. Byungil Kim, Kyeongseok Kim, Changyoon Kim, 'Determining the optimal installation timing of building integrated photovoltaic systems', Journal of Cleaner Production, Vol. 140, Part 3, 1 January 2017, pp. 1322-1329

4. Akash Kumar Shukla, K. Sudhakar, Prashant Baredar, 'A comprehensive review on design of building integrated photovoltaic system', Energy and Buildings, Vol. 128, 15 September 2016, pp 99110

5. Chr. Lamnatou, G. Notton, D. Chemisana, C. Cristofari, 'Review: Storage systems for building-integrated photovoltaic (BIPV) and building-integrated photovoltaic/thermal (BIPVT) installations: Environmental profile and other aspects', Science of The Total Environment, Vol. 699, 10 January 2020, 134269

6. Xun Ma, Ming Li, Liwei Du, Benqian Qin, Yunfeng Wang, Xi Luo, Guoliang Li, 'Online extraction of physical parameters of photovoltaic modules in a building-integrated photovoltaic system', Energy Conversion and Management, Vol. 199, 1 November 2019, 112028

7. Tareq Salameh, Mamdouh El Haj Assad, Muhammad Tawalbeh, Chaouki Ghenai, Adel Merabet, Hakan F. Öztop, 'Analysis of cooling load on commercial building in UAE climate using building integrated photovoltaic façade system', Solar Energy, Vol. 199, 15 March 2020, pp. 617-629

8. Somil Yadav, S.K. Panda, Caroline Hachem-Vermette, 'Method to improve performance of building integrated photovoltaic thermal system having optimum tilt and facing directions', Applied Energy, Vol. 266, 15 May 2020, 114881

9. Tingting Yang, Andreas K.Athienitis, 'A review of research and developments of building-integrated photovoltaic/thermal (BIPV/T) systems', Renewable and Sustainable Energy Reviews, Vol. 66, December 2016, pp. 886-912

10. Roberta Zarcone, Maurizio Brocato, Paolo Bernardoni, Donato Vincenzi, 'Building Integrated Photovoltaic System for a Solar Infrastructure: Liv-lib' Project', Energy Procedia, Vol. 91, June 2016, pp. 887-896

11. M.Fouad, Lamia A.Shihata, A.H.Mohamed, 'Modeling and analysis of Building Attached Photovoltaic Integrated Shading Systems (BAPVIS) aiming for zero energy buildings in hot regions' Journal of Building Engineering, Vol. 21, January 2019, pp. 18-27

12. Aritra Ghosh, Nabin Sarmah, Senthilarasu Sundaram, Tapas K.Mallick, 'Numerical studies of thermal comfort for semitransparent building integrated photovoltaic (BIPV)-vacuum glazing system', Solar Energy, Vol. 190, 15 September 2019, pp. 608-616

13. Quan Sui, Fanrong Wei, Rui Zhang, Xiangning Lin, Ning Tong, Zhixun Wang, Zhengtian Li, 'Optimal use of electric energy-oriented water-electricity combined supply system for the buildingintegrated-photovoltaics community', Applied Energy, Vol. 247, 1 August 2019, pp. 549-558

14. Mohan Lal Kolhe, M.J.M.A.Rasul, '3-Phase grid-connected building integrated photovoltaic system with reactive power control capability', Renewable Energy, Vol. 154, July 2020, pp. 1065-1075

15. Rafaela A. Agathokleous, Soteris A. Kalogirou, 'Status, barriers and perspectives of building integrated photovoltaic systems', Energy, Vol. 191, 15 January 2020, 116471

16. Hassan Gholami, Harald Nils Røstvik, Daniela Müller-Eie, 'Holistic economic analysis of building integrated photovoltaics (BIPV) system: Case studies evaluation', Energy and Buildings, Vol. 203, 15 November 2019, 109461

17. S.S.S.Baljit, Hoy-Yen Chan, Kamaruzzaman Sopian, 'Review of building integrated applications of photovoltaic and solar thermal systems', Journal of Cleaner Production, Vol. 137, 20 November 2016, pp. 677-689 
18. Bernadette Fina, Hans Auer, Werner Friedl, 'Profitability of active retrofitting of multi-apartment buildings: Buildingattached/integrated photovoltaics with special consideration of different heating systems', Energy and Buildings, Vol. 190, 1 May 2019, pp. 86-102

19. Arthur Mariaud, Salvador Acha, Ned Ekins-Daukes, Nilay Shah, Christos N.Markides, 'Integrated optimisation of photovoltaic and battery storage systems for UK commercial buildings', Applied Energy, Vol. 199, 1 August 2017, pp. 466-478

20. U.Mazzali, P.Ruggeri, M.Zinzi, F.Peron, P.Romagnoni, A.Daneo, 'Set-up and Calibration by Experimental Data of a Numerical Model for the Estimation of Solar Factor and $U_{\mathrm{g}}$-value of Building Integrated Photovoltaic Systems', Energy Procedia, Vol. 78, November 2015, pp. 2202-2207

21. Yongqiang Luo, Ling Zhang, Zhongbing Liu, Yingzi Wang, Fangfang Meng, Jing Wu, 'Thermal performance evaluation of an active building integrated photovoltaic thermoelectric wall system', Applied Energy, Vol. 177, 1 September 2016, pp. 25-39

22. Hassan Fathabadi, 'Increasing energy efficiency of PV-converterbattery section of standalone building integrated photovoltaic systems', Energy and Buildings, Vol. 101, 15 August 2015, pp. 1-11

23. Andreas K. Athienitis, Giovanni Barone, Annamaria Buonomano, Adolfo Palombo, 'Assessing active and passive effects of façade building integrated photovoltaics/thermal systems: Dynamic modelling and simulation', Applied Energy, Vol. 209, 1 January 2018, pp. 355-382

24. D.Roeleveld, G.Hailu, A.S.Fung, D.Naylor, T.Yang, A.K.Athienitis, 'Validation of Computational Fluid Dynamics (CFD) Model of a Building Integrated Photovoltaic/Thermal (BIPV/T) System', Energy Procedia, Vol. 78, November 2015, pp. 1901-1906

25. Ya Brigitte Assoa, Leon Gaillard, Christophe Ménézo, Nicolas Negri, François Sauzedde, 'Dynamic prediction of a building integrated photovoltaic system thermal behaviour', Applied Energy, Vol. 214, 15 March 2018, pp. 73-82

26. Wei Gao, Hossein Moayedi, Amin Shahsavar, 'The feasibility of genetic programming and ANFIS in prediction energetic performance of a building integrated photovoltaic thermal (BIPVT) system', Solar Energy, Vol. 183, 1 May 2019, pp. 293-305

27. Mahsa Khaki, Amin Shahsavar, Shoaib Khanmohammadi, Mazyar Salmanzadeh, 'Energy and exergy analysis and multi-objective optimization of an air-based building integrated photovoltaic/thermal (BIPV/T) system', Solar Energy, Vol. 158, December 2017, pp. 380-395

28. Abdulwahab A.Alnaqi, Hossein Moayedi, Amin Shahsavar, Truong Khang Nguyen, 'Prediction of energetic performance of a building integrated photovoltaic/thermal system thorough artificial neural network and hybrid particle swarm optimization models', Energy Conversion and Management, Vol.183, 1 March 2019, pp 137-148

29. Jia Liu, Xi Chen, Hongxing Yang, Yutong Li, 'Energy storage and management system design optimization for a photovoltaic integrated low-energy building', Energy, Vol. 190, 1 January 2020, 116424

30. Getu Hailu, Peter Dash, Alan S.Fung, 'Performance Evaluation of an Air Source Heat Pump Coupled with a Building-Integrated Photovoltaic/Thermal (BIPV/T) System under Cold Climatic Conditions', Energy Procedia, Vol. 78, November 2015, pp. 19131918

31. Siwei Li, Jaewan Joe, Jianjun Hu, Panagiota Karava, 'System identification and model-predictive control of office buildings with integrated photovoltaic-thermal collectors, radiant floor heating and active thermal storage', Solar Energy, Vol. 113, March 2015, pp. $139-157$

32. G.N.Tiwari, Hemshikha Saini, Arvind Tiwari, Arjun Deo, Neha Gupta, Padamveer Singh Saini, 'Periodic theory of building integrated photovoltaic thermal (BiPVT) system', Solar Energy, Vol. 125, February 2016, pp. 373-380

33. Arjun Deo, G.K.Mishra, G.N.Tiwari, 'A thermal periodic theory and experimental validation of building integrated semi-transparent photovoltaic thermal (BiSPVT) system', Solar Energy, Vol. 155, October 2017, pp. 1021-1032

34. G.K.Mishra, G.N.Tiwari, T.S.Bhatti, 'Effect of water flow on performance of building integrated semi-transparent photovoltaic thermal system: A comparative study', Solar Energy, Vol. 174, 1 November 2018, pp. 248-262

35. Neha Gupta, G.N.Tiwari, 'Effect of water flow on building integrated semitransparent photovoltaic thermal system with heat capacity', Sustainable Cities and Society, Vol. 39, May 2018, pp. 708-718

36. Yongqiang Luo, Ling Zhang, Zhongbing Liu, Jing $\mathrm{Wu}$, Xiliang Wang, Lei Xie, Xiu Xu, Xiaohui Lv, 'Building Integrated
Photovoltaic Thermoelectric Wall System: Balancing Simulation Speed and Accuracy', Energy Procedia, Vol. 105, May 2017, pp 8893

37. Zhongting Hu, Wei He, Jie Ji, Dengyun Hu, Song Lv, Hongbing Chen, Zhihe Shen, 'Comparative study on the annual performance of three types of building integrated photovoltaic (BIPV) Trombe wall system', Applied Energy, Vol. 194, 15 May 2017, pp. 81-93

38. Yongqiang Luo, Ling Zhang, Jing Wu, Zhongbing Liu, Zhenghong $\mathrm{Wu}$, Xihua $\mathrm{He}$, 'Dynamical simulation of building integrated photovoltaic thermoelectric wall system: Balancing calculation speed and accuracy', Applied Energy, Vol. 204, 15 October 2017, pp. 887-897

39. M.Tripathy, S.Yadav, S.K.Panda, P.K.Sadhu, 'Performance of building integrated photovoltaic thermal systems for the panels installed at optimum tilt angle', Renewable Energy, Vol. 113, December 2017, pp. 1056-1069

40. Rafaela A.Agathokleous, Soteris A.Kalogirou, Sotirios Karellas, 'Exergy analysis of a naturally ventilated Building Integrated Photovoltaic/Thermal (BIPV/T) system', Renewable Energy, Vol. 128, Part B, December 2018, pp. 541-552

41. Mohamed Ahmed-Dahmane, Ali Malek, Tahar Zitoun, 'Design and analysis of a BIPV/T system with two applications controlled by an air handling unit', Energy Conversion and Management, Vol. 175, 1 November 2018, pp. 49-66

42. Tingting Yang, Andreas K.Athienitis, 'Experimental investigation of a two-inlet air-based building integrated photovoltaic/thermal (BIPV/T) system', Applied Energy, Vol. 159, 1 December 2015, pp. 70-79

43. Efstratios Dimitrios Rounis, Andreas K.Athienitis, Theodore Stathopoulos, 'Multiple-inlet Building Integrated Photovoltaic/Thermal system modelling under varying wind and temperature conditions', Solar Energy, Vol. 139, 1 December 2016, pp. $157-170$

44. Bin Zhao, Mingke Hu, Xianze Ao, Nuo Chen, Qingdong Xuan, Yuehong Su, Gang Pei, 'A novel strategy for a building-integrated diurnal photovoltaic and all-day radiative cooling system', Energy, Vol. 183, 15 September 2019, pp. 892-900

45. Bin Zhao, Mingke Hu, Xianze Ao, Gang Pei, 'Conceptual development of a building-integrated photovoltaic-radiative cooling system and preliminary performance analysis in Eastern China', Applied Energy, Vol. 205, 1 November 2017, pp. 626-634

46. Long Hui, Chow Tin-Tai, Ji Jie, 'Building-integrated heat pipe photovoltaic/thermal system for use in Hong Kong', Solar Energy, Vol. 155, October 2017, pp. 1084-1091

47. Shoaib Khanmohammadi, Amin Shahsavar, 'Energy analysis and multi-objective optimization of a novel exhaust air heat recovery system consisting of an air-based building integrated photovoltaic/thermal system and a thermal wheel', Energy Conversion and Management, Vol. 172, 15 September 2018, pp. 595-610

48. Karen Connelly, Yupeng Wu, Jun Chen, Yu Lei, 'Design and development of a reflective membrane for a novel Building Integrated Concentrating Photovoltaic (BICPV) 'Smart Window' system', Applied Energy, Vol. 182, 15 November 2016, pp. 331-339

49. Yongqiang Luo, Ling Zhang, Zhongbing Liu, Jing Wu, Yelin Zhang, Zhenghong Wu, Xihua He, 'Performance analysis of a self-adaptive building integrated photovoltaic thermoelectric wall system in hot summer and cold winter zone of China', Energy, Vol. 140, Part 1, 1 December 2017, pp. 584-600

50. Z.X. Li, Amin Shahsavar, Abdullah A.A.A. Al-Rashed, Rasool Kalbasi, Masoud Afrand, Pouyan Talebizadeh Sardari, 'Multiobjective energy and exergy optimization of different configurations of hybrid earth-air heat exchanger and building integrated photovoltaic/thermal system', Energy Conversion and Management, Vol. 195, 1 September 2019, pp. 1098-1110

51. Masoud Afrand, Amin Shahsavar, Pouyan Talebizadeh Sardari, Kamaruzzaman Sopian, Hamzeh Salehipour, 'Energy and exergy analysis of two novel hybrid solar photovoltaic geothermal energy systems incorporating a building integrated photovoltaic thermal system and an earth air heat exchanger system', Solar Energy, Vol. 188 , August 2019, pp. 83-95

52. C.S.Rajoria, Sanjay Agrawal, Subhash Chandra, G.N.Tiwari, D.S.Chauhan, 'A Novel investigation of building integrated photovoltaic thermal (BiPVT) system: A comparative study', Solar Energy, Vol. 131, June 2016, pp. 107-118

53. G.K.Mishra, G.N.Tiwari, 'Performance evaluation of $7.2 \mathrm{~kW}_{\mathrm{p}}$ standalone building integrated semi-transparent photovoltaic thermal system', Renewable Energy, Vol. 146, February 2020, pp. 205-222 
54. Johwa Yang, Hyunjin Jo, Soo-Won Choi, Dong-Won Kang, JungDae Kwon, 'Adoption of wide-bandgap microcrystalline silicon oxide and dual buffers for semitransparent solar cells in buildingintegrated photovoltaic window system', Journal of Materials Science \& Technology, Vol. 35, Issue 8, August 2019, pp. 15631569

55. Neha Gupta, Arvind Tiwari, G.N.Tiwari, 'A thermal model of hybrid cooling systems for building integrated semi-transparent photovoltaic thermal system', Solar Energy, Vol. 153, 1 September 2017, pp. 486-498

56. Neha Gupta, G.N.Tiwari, 'Parametric study to understand the effect of various passive cooling concepts on building integrated semitransparent photovoltaic thermal system', Solar Energy, Vol.180, 1 March 2019, pp. 391-400

57. Qingdong Xuan, Guiqiang Li, Yashun Lu, Bin Zhao, Xudong Zhao, Yuehong Su, Jie Ji, Gang Pei, 'Overall detail comparison for a building integrated concentrating photovoltaic/daylighting system', Energy and Buildings, Vol. 199, 15 September 2019, pp. 415-426

58. Homan Hadavinia, Harjit Singh, 'Modelling and experimental analysis of low concentrating solar panels for use in building integrated and applied photovoltaic (BIPV/BAPV) systems', Renewable Energy, Vol. 139, August 2019, pp. 815-829

59. Hasan Baig, Daniel Chemisana, Senthilarasu Sundaram, Tapas Mallick, 'Conjugate refractive-reflective based building integrated photovoltaic system', Materials Letters, Vol. 228, 1 October 2018, pp. $25-28$

60. Hasan Baig, Nazmi, Sellami, Tapas K.Mallick, 'Performance modeling and testing of a Building Integrated Concentrating Photovoltaic (BICPV) system', Solar Energy Materials and Solar Cells, Vol. 134, March 2015, pp. 29-44

61. Konstantinos Spiliotis, Juliana E. Gonçalves, Dirk Saelens, Kris Baert, Johan Driesen, 'Electrical system architectures for buildingintegrated photovoltaics: A comparative analysis using a modelling framework in Modelica', Applied Energy, Vol. 261, 1 March 2020, 114247

62. Wendelin Sprenger, Helen Rose Wilson, Tilmann E.Kuhn, 'Electricity yield simulation for the building-integrated photovoltaic system installed in the main building roof of the Fraunhofer Institute for Solar Energy Systems ISE', Solar Energy, Vol. 135, October 2016 pp. 633-643

63. Yunyun Wang, Shanming Ke, Fengshou Liu, Junfei Li, Gang Pei, 'Performance of a building-integrated photovoltaic/thermal system under frame shadows', Energy and Buildings, Vol. 134, 1 January 2017, pp. 71-79

64. S.Yadav, S.K.Panda, M.Tripathy, 'Performance of building integrated photovoltaic thermal system with PV module installed at optimum tilt angle and influenced by shadow', Renewable Energy, Vol. 127, November 2018, pp. 11-23

65. Mohammed A.M.Yassin, Mohan Kolhe, Arvind Sharma, Shirish Garud, "Battery Capacity Estimation for Building Integrated Photovoltaic System: Design Study for Different Geographical Location(s)', Energy Procedia, Vol. 142, December 2017, pp. 34333439

66. Pooja Sharma, Mohan Kolhe, Arvind Sharma, 'Economic performance assessment of building integrated photovoltaic system with battery energy storage under grid constraints', Renewable Energy, Vol. 145, January 2020, pp. 1901-1909

67. A.Karthick, K.Kalidasa Murugavel, Aritra Ghosh, K.Sudhakar, P.Ramanan, 'Investigation of a binary eutectic mixture of phase change material for building integrated photovoltaic (BIPV) system', Solar Energy Materials and Solar Cells, Vol. 207, April 2020, 110360

68. K.Kant, R.Pitchumani, A.Shukla, A.Sharma, 'Analysis and design of air ventilated building integrated photovoltaic (BIPV) system incorporating phase change materials', Energy Conversion and Management, Vol. 196, 15 September 2019, pp. 149-164

69. Shivangi Sharma, Asif Tahir, K.S.Reddy, Tapas K.Mallick, 'Performance enhancement of a Building-Integrated Concentrating Photovoltaic system using phase change material', Solar Energy Materials and Solar Cells, Vol. 149, May 2016, pp. 29-39

70. Ahmad Hasan, Hamza Alnoman, Yasir Rashid, 'Impact of integrated photovoltaic-phase change material system on building energy efficiency in hot climate', Energy and Buildings, Vol. 130, 15 October 2016, pp. 495-505

71. Amin Shahsavar, Yalda Rajabi, 'Exergoeconomic and enviroeconomic study of an air-based building integrated photovoltaic/thermal (BIPV/T) system', Energy, Vol. 144, 1 February 2018, pp. 877-886

72. Neha Gupta, Arvind Tiwari, G.N.Tiwari, 'Exergy analysis of building integrated semitransparent photovoltaic thermal (BiSPVT) system', Engineering Science and Technology, an International Journal, Vol. 20, Issue 1, February 2017, pp. 41-50

73. Ankita Gaur, G.N.Tiwari, Christophe Ménézo, I.M.Al-Helal, 'Numerical and experimental studies on a Building integrated Semitransparent Photovoltaic Thermal (BiSPVT) system: Model validation with a prototype test setup', Energy Conversion and Management, Vol. 129, 1 December 2016, pp. 329-343

74. Mustafa Araz, Arif Hepbasli, Emrah Biyik, Mehdi Shahrestani, Runming Yao, Emmanuel Essah, Li Shao, Armando C.Oliveira, Orhan Ekren, Hüseyin Günerhan, 'Performance evaluation of a building integrated photovoltaic (BIPV) system combined with a wastewater source heat pump (WWSHP) system', Energy Procedia, Vol. 140, December 2017, pp. 434-446

75. S. Rasoul Asaee, Sara Nikoofard, V. Ismet Ugursal, Ian BeausoleilMorrison, 'Techno-economic assessment of photovoltaic (PV) and building integrated photovoltaic/thermal (BIPV/T) system retrofits in the Canadian housing stock', Energy and Buildings, Vol. 152, 1 October 2017, pp. 667-679

76. Didier Sierra, Andrés Julián Aristizábal, Jesús Antonio Hernández, Daniel Ospina, 'Life cycle analysis of a building integrated photovoltaic system operating in Bogotá, Colombia', Energy Reports, Vol. 6, Suppl. 3, February 2020, pp. 10-19

77. Kashif Irshad, Khairul Habib, Salem Algarni, Bidyut Baran Saha, Basharat Jamil, 'Sizing and life-cycle assessment of building integrated thermoelectric air cooling and photovoltaic wall system', Applied Thermal Engineering, Vol. 154, 25 May 2019, pp. 302-314

78. M.Tripathy, H.Joshi, S.K.Panda, 'Energy payback time and lifecycle cost analysis of building integrated photovoltaic thermal system influenced by adverse effect of shadow', Applied Energy, Vol. 208, 15 December 2017, pp. 376-389

79. Dikai Huang, Tai Yu, 'Study on Energy Payback Time of Building Integrated Photovoltaic System', Procedia Engineering, Vol. 205, 2017, pp. 1087-1092

80. Ya Brigitte Assoa, François Sauzedde, Benjamin Boillot, Simon Boddaert, 'Development of a building integrated solar photovoltaic/thermal hybrid drying system', Energy, Vol. 128, 1 June 2017, pp. $755-767$ 